\title{
POLÍTICAS HABITACIONAIS NACIONAIS: Os Desafios ao Direito de Moradia nos Arranjos Institucionais do Programa Minha Casa Minha Vida
}

http://dx.doi.org/10.21527/2176-6622.2021.56.12080

Recebido em: 24/2/2021

Modificações solicitadas em: 5/4/2021

Aceito em: 19/4/2021

\author{
Sergio Alexandre de Moraes Braga Junior \\ Universidade do Estado do Rio Grande do Norte (UERN). Campus Avançado de Natal. \\ Av. Dr. João Medeiros Filho, 3419 - Potengi. Natal/RN, Brasil. CEP 59120-200 \\ Universidade Federal do Rio Grande do Norte (UFRN). Campus Universitário - Lagoa Nova. \\ Natal/RN, Brasil. CEP 59078-970. https://orcid.org/0000-0001-8716-7468. \\ http://lattes.cnpq.br/8429436981406857. s.alexandre.prof@gmail.com
}

\section{RESUMO}

O presente trabalho tem como tema o enfrentamento dos desafios ao direito à moradia com foco em políticas habitacionais nacionais. Nesse sentido, tem como objetivo analisar os arranjos institucionais no âmbito do programa habitacional "Minha Casa Minha Vida" sob o viés da ampliação da participação nesse programa e da viabilização do alcance dos objetivos propostos. Tal exame considerará a inserção do referido programa no contexto da organização jurídico-institucional da política urbana em âmbito nacional. Questiona-se, inicialmente, na discussão da problemática: As políticas habitacionais nacionais atenderam ao direito da moradia, em especial o programa "Minha Casa Minha Vida"? A metodologia seguirá o método indutivo e revisão da bibliografia e dos atos normativos relevantes ao tema. De início, situar-se-á como política pública o programa "Minha Casa Minha Vida" e a inclusão da moradia entre o rol dos direitos fundamentais após a Emenda Constitucional no 26/2000. Em seguida, enfatizar-se-á o empenho legislativo no sentido de garantir o direito à moradia, com vistas à harmonização entre os direitos individuais e coletivos e os processos de desenvolvimento econômico e preservação do meio ambiente, enfatizando o papel do Estatuto da Cidade na consolidação desse direito fundamental. Avalia-se, como resultado, como a dinâmica do programa habitacional em questão lida com os fenômenos da cidade ilegal e da exclusão social e com as demandas advindas dos movimentos sociais relacionados à moradia, de forma a tecer conclusão acerca do grau de êxito desse programa no sentido de contribuir para a garantia e fortalecimento do direito à moradia no contexto pátrio.

Palavras-chave: Direito de moradia; políticas habitacionais; políticas públicas; Minha Casa Minha Vida.

\section{NATIONAL HABITATIONAL POLICIES: THE CHALLENGES ON THE RIGHT TO HABITATION IN THE} INSTITUTIONAL ARRANGEMENTS OF THE MINHA CASA MINHA VIDA PROGRAM

\section{ABSTRACT}

The theme of the present work is the confrontation of the challenges to the right to habitation, with focus on national habitational policies. In this sense, the objective is to analise the institutional arrangements made under the "Minha Casa Minha Vida" habitational program with focus on the increase of participation in the program and in the enabling of the proposed objectives. This exam will consider the program in the context of the legal-institutional structure of the urban policy at a national level. It is questioned, initially, in the discussion of the problem: did the national housing policies meet the housing law, especially the "Minha Casa, Minha Vida" program? The metodology will follow the inductive method, Initially, the "Minha Casa Minha Vida" program will be established as a public policy, aswell as the inclusion of habitation among the fundamental rights following the emenda constitucional $n=26 / 2000$. Following that, the legislative efforts to guarantee the right to habitation will be highlighted, with them focusing on the harmonization between individual and collective rights and the processes of economic development and enviromental preservation, emphasizing the role of the Estatuto da Cidade in the consolidation of this fundamental right. It will then be evaluated, as a result, how the dynamics of the habitational program in question deals with the phenomena of ilegal cities and social exclusion, and likewise with the demands of the social movements related to habitation, to enable a conclusion about the program's level of success in regards to contributing to the strenghtening and the asserting of the right to habitation in the local context.

Keywords: Right to habitation; habitational policies; public policies; Minha Casa Minha Vida. 


\section{Direito \\ Debate}

POLÍTICAS HABITACIONAIS NACIONAIS:

OS DESAFIOS AO DIREITO DE MORADIA NOS ARRANJOS INSTITUCIONAIS DO PROGRAMA MINHA CASA MINHA VIDA

Sergio Alexandre de Moraes Braga Junior

\section{INTRODUÇÃO}

Este trabalho focaliza os arranjos institucionais do programa habitacional do país, denominado "Minha Casa Minha Vida" (PMCMV), examinando-os tanto do ponto de vista democrático quanto de sua efetividade para alcançar os objetivos propostos. Ou seja, indaga se tais arranjos incentivam ou não a participação mais ampla de uma pluralidade de atores e se eles favorecem ou não a instituição do programa e o alcance das metas propostas. Segundo Loureiro, Macário e Guerra ${ }^{1}$, por arranjos institucionais entende-se o conjunto de regras, organizações e processos que definem a forma como se coordenam os atores e os interesses em pauta em uma determinada política pública.

O tema desta pesquisa será tratar, como objetivo maior, do desafio do direito à moradia, com foco nas políticas nacionais de habitação. Nesse sentido, objetiva-se, ainda, analisar os arranjos institucionais no âmbito do plano habitacional "Minha Casa Minha Vida", com o viés de ampliar a participação no plano e atingir as metas propostas. Essa revisão considerará a inserção dos referidos arranjos no âmbito da organização do sistema jurídico da política urbana em âmbito nacional.

Observa-se, na problemática aferida, ao se debater o assunto, se as políticas nacionais de habitação atendem ou não às necessidades sociais do direito à moradia, em especial o Programa "Minha Casa Minha Vida", no trato de populações desfavorecidas por políticas públicas anteriores, em seu caráter inclusivo.

Metodologicamente, utilizar-se-á o método indutivo, quando será feita uma revisão da bibliografia, além do comportamento normativo e estrutural das ações estatais relacionados ao assunto. Inicialmente, observar-se-á o Programa "Minha Casa Minha Vida" e a inclusão da moradia no rol dos direitos básicos, após a Emenda Constitucional no 26/2000, como pressupostos de políticas públicas.

A Emenda Constitucional $n^{\circ}$ 26/2000 deu nova redação ao caput do artigo $6^{\circ}$ da Constituição Federal de 1988 (CF/1988), alçando o direito à moradia à condição de garantia constitucional, e a promulgação da lei n¹0.257/2001 (Estatuto da Cidade), em cumprimento aos artigos 182 e 183 da CF/1988, organizou a política urbana em âmbito federal, oferecendo parte do arcabouço jurídico-institucional.

Além da criação do Ministério das Cidades, o governo Lula trouxe outras importantes inovações institucionais na área, concretizadas na lei $n^{\circ} 11.124$, de 2005, que cria o conselho nacional das cidades, o Sistema Nacional de Habitação de Interesse Social (SNHIS), incluindo o fundo de financiamento e estabelecendo as bases para a formulação do Plano Nacional de Habitação (Planhab) que apostava no fortalecimento do planejamento democrático das cidades e, como será visto a seguir, contribuiu de alguma forma no desenho do PMCMV, ao indicar que o déficit habitacional do país se concentrava, sobretudo, na população de renda mais baixa.

O Conselho das Cidades é considerado "a materialização de um importante instrumento de gestão democrática da Política Nacional de Desenvolvimento Urbano (PNDU), então em processo de construção". ${ }^{2}$

No ano de 2007 foi lançado o Programa de Aceleração do Crescimento-PAC, com o objetivo de se alcançar um crescimento em infraestrutura social, urbana, logística e energética no Brasil, de forma contínua e acelerada. O PAC caracteriza-se não por ser apenas um projeto de infraestrutura, mas também por envolver diferentes setores do governo federal, quando diferentes atores participavam das tomadas de decisão. Lotta e Favaretto ${ }^{3}$ apontam dificuldades sobre a gestão de infraestrutura, que vem afetar diretamente a execução das obras.

LOUREIRO, Maria Rita; MACÁRIO, Vinícius; GUERRA, Pedro Henrique. Legitimidade e efetividade em arranjos institucionais de políticas públicas: o Programa Minha Casa Minha Vida. Rev. Adm. Pública, Rio de Janeiro, 49(6), p. 1.531-1.554, nov./dez. 2015.

Ibidem.

3 LOTTA, Gabriela; FAVARETTO, Arilson. Os arranjos institucionais dos investimentos em infraestrutura no Brasil: uma análise sobre seis grandes projetos do Programa de Aceleração de Crescimento. Texto para Discussão, Ipea, 2.253, nov. 2016. 
POLÍTICAS HABITACIONAIS NACIONAIS:

OS DESAFIOS AO DIREITO DE MORADIA NOS ARRANJOS INSTITUCIONAIS DO PROGRAMA MINHA CASA MINHA VIDA Sergio Alexandre de Moraes Braga Junior

Flyvbjerg, Bruzelius e Rochengatter ${ }^{4}$ fortalecem a perspectiva de que um satisfatório processo decisório envolve arranjos institucionais que permeiem a participação do cidadão e políticos (accountability), tornando os processos com maiores resultados positivos.

Pires e Gomide ${ }^{5}$ fornecem quatro pontos voltados para a política de desenvolvimento. 0 primeiro refere-se à lógica da política que permeia o Estado pós-CF/1988; o segundo trata-se da descentralização política administrativa; o terceiro diz respeito às garantias de direitos individuais, coletivos e difusos e o último é voltado para a construção de um ambiente institucional que incorpore a participação social nos processos de formulação e controle das políticas públicas.

Thiago Moreira ${ }^{6}$ aborda os atores constituídos dentro do próprio Estado, comprometidos com projetos que visam a fortalecer as instituições que integram e as políticas públicas que exercem, fazendo com que os leitores reflitam acerca da ligação existente entre as instituições e suas respectivas políticas públicas, como forma de concretização do próprio Estado.

\section{AS POLÍTICAS PÚBLICAS E A ATUAÇÃO DO ESTADO}

Eduardo Cesar Marques ${ }^{7}$ traz à baila dois atores relevantes para explicar o processo de produção e instalação das políticas públicas no contexto da contemporaneidade: os agentes estatais e as corporações profissionais. A importância atribuída a estes novos atores decorre da contribuição da literatura neoinstitucionalista, dos estudos da análise setorial e da abordagem do Estado na sociedade.

Nesta compreensão, o Estado reaparece na condição de ator relativamente autônomo, de onde emergem os grupos de agentes estatais - funcionários públicos de carreira alijados das disputas e dos interesses das sociedade - que, conforme aponta Marques, ${ }^{8}$ seriam capazes de produzir políticas públicas (outputs) para além daquelas preconizadas pelos atores e grupos de interesses (inputs), revelando a relevância destes atores no processo de produção das políticas na medida na medida em que se mantém-se relativamente insulados dos interesses da sociedade e da contingência política.

Seja ontológica, seja epistemológica, o que interessa é a utilidade do conceito de incerteza para o ferramental de North ${ }^{9}$. Ao impedir que os agentes conheçam todo o seu rol de possibilidades de escolha de forma ex ante, esta torna-se responsável por interrupções ou "mau funcionamento" das transações econômicas, fazendo com que os agentes sejam incapazes de atingir soluções ótimas a partir de suas decisões.

Na designação de políticas públicas Schmidt ${ }^{10}$ leciona:

Embora na prática os governos nem sempre sigam a sequência política - plano - programa - projeto - ação, a adoção dessa terminologia tem a vantagem de ajudar a consagrar o conceito de políticas públicas como um conjunto de ações destinadas a resolver um problema político e não como qualquer ação da gestão pública.

\footnotetext{
4 FLYVBJERG, Bent; BRUZELIUS, Nils; ROTHENGATTER, Werner. Megaprojects and risk: an anatomy of ambition. Cambridge: Cambridge University Press, 2003

5 PIRES, Roberto; GOMIDE, Alexandre. Governança e capacidades estatais: uma análise comparativa de programas federais. Rev. Sociol. Polit., v. 24, n. 58, p. 121-143, jun. 2016.

6 MOREIRA, Thiago de Miranda Queiroz. Disputas Institucionais e Interesses corporativos no Sistema de Justiça: impasses na criação da Defensoria Pública nos Estados. Dados, Rio de Janeiro, v. 62, n. 4, e20170071, 2019.

7 MARQUES, Eduardo. Notas críticas à literatura sobre Estado, políticas estatais e atores políticos. BIB, Rio de Janeiro, n. 43, 1ㅇsemestre de 1997.

8 MARQUES, Eduardo. Notas críticas à literatura sobre Estado, políticas estatais e atores políticos. BIB, Rio de Janeiro, n. 43, 1으 semestre de 1997.

9 NORTH, Douglass. Instituições, mudança institucional e desempenho econômico. São Paulo: Três Estrelas, 2018.

${ }^{10}$ SCHMIDT, João Pedro. Para estudar políticas públicas: aspectos conceituais, metodológicos e abordagens teóricas. Revista do Direito, Santa Cruz do Sul, v. 3, n. 56, jan. 2019.
} 
POLÍTICAS HABITACIONAIS NACIONAIS:

OS DESAFIOS AO DIREITO DE MORADIA NOS ARRANJOS INSTITUCIONAIS DO PROGRAMA MINHA CASA MINHA VIDA

Sergio Alexandre de Moraes Braga Junior

Entende-se por políticas públicas ${ }^{11}$ o conjunto de programas, ações e decisões tomadas pelo governo em âmbito nacional, estadual ou municipal por meio dos entes públicos, admitida a participação, direta ou indireta, de entes privados que buscam garantir um determinado direito assegurados na Constituição Federal de 1988 para os mais variados grupos da sociedade ou para determinado segmento social, cultural, étnico ou econômico.

Sobre as políticas públicas Maria Paula Dallari Bucci ${ }^{12}$ aduz:

[...] são programas de ação governamental visando a coordenar os meios à disposição do Estado e as atividades privadas, para a realização de objetivos socialmente relevantes e politicamente determinados.

Ainda, vale entender que as políticas públicas possuem um papel fundamental, pois são garantidoras da cidadania. Esta, por sua vez, é elemento essencial dentro de um Estado Democrático de Direito, posto que é deste que nascem inúmeras obrigações do Estado em garantir direitos essenciais aos cidadãos, entre os quais estão aqueles principais, como o direito à vida, à liberdade, à igualdade, à segurança e outros.

Meny e Toenig, tratando o tema, por sua vez, definiram que "uma política pública é o resultado da atividade de uma autoridade investida de poder público e de legitimidade governamental". ${ }^{13}$

Figueiredo e Limongi, ${ }^{14}$ ao questionarem as mudanças institucionais, desfazem o mito de que o Legislativo seria obstaculizante à agenda do Executivo e revelam as fragilidades deste poder em dois sentidos: de suas funções institucionais no quadro da divisão de poderes do Estado e na ineficiência de sua organização interna.

Immergut, ${ }^{15}$ por sua vez, observa que no cenário em que se tem um Executivo mais forte e com plena estabilidade, suas propostas são encaminhadas e aprovadas com mais facilidade pelo poder Legislativo sem grande interferência dos grupos de interesses, como é o caso da Suécia. A análise de Immergut sobre o sistema de saúde nos três países da Europa defende que as normas constitucionais que regem as instituições de cada país são capazes de influenciar no processo de aprovação da política pública - no caso específico do ensaio, de um seguro social de saúde - conseguindo inibir ou maximizar a capacidade de influência dos grupos de interesse.

Segundo Schmidt, ${ }^{16}$ a agenda é um constante processo de mutação, pois "a agenda política nunca está dada. Não há uma agenda "natural". Trata-se de uma construção permanente, que envolve constante disputa. Na construção da agenda governamental destacam-se agentes governamentais e não governamentais".

A influência de grupos de interesses é amplamente discutida na literatura de formação da agenda, como o poder que as comunidades de políticas de Kingdon ${ }^{17}$ possuem em deliberar sobre determinada área.

Subirats ${ }^{18}$ acaba por apresentar um conjunto sistematizado de fatores, elementos ou componentes que influenciam ou ordenam essas políticas: confiança, direito, pessoal, informação e conhecimento, dinheiro, infraestrutura, organização, tempo e força.

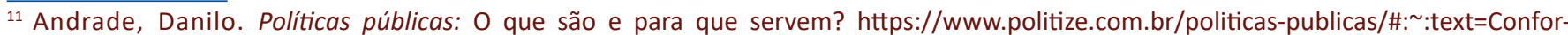
me\%20defini\%C3\%A7\%C3\%A30\%20corrente\%2C\%20pol\%C3\%ADticas\%20p\%C3\%BAblicas,grupos\%20da\%20sociedade\%20ou\%20para. Acesso em: 4 fev. 2016.

12 BUCCI, Maria Paula Dallari (org.). Políticas públicas - reflexões sobre o conceito jurídico. São Paulo: Saraiva, 2006. p. 241.

${ }^{13}$ MENY, Yves; THOENIG, Jean-Claude. Las políticas públicas. Barcelona: Ariel, 1992.

${ }^{14}$ FIGUEIREDO, Argelina; LIMONGI, Fernando. Mudança constitucional, desempenho do legislativo e consolidação institucional. In: FIGUEIREDO, Argelina; LIMONGI, Fernando. Executivo e legislativo na nova ordem constitucional. 2. ed. Rio de Janeiro: FGV, 1999. p. 41-72. Cap. 2.

${ }^{15}$ IMMERGUT, Ellen M. As regras do jogo: a lógica da política de saúde na França, na Suíça e na Suécia. Revista Brasileira de Ciências Sociais, v. 30, n. 11, p. 139-163, 1996.

${ }^{16}$ SCHMIDT, João Pedro. Para estudar políticas públicas: aspectos conceituais, metodológicos e abordagens teóricas. Revista do Direito, Santa Cruz do Sul, v. 3, n. 56, jan. 2019.

17 KINGDON, John W. Agendas, Alternatives, and Public Policies. Segunda edição. Nova York, Harper Collins College Publishers. 1995.

${ }^{18}$ SUBIRATS, Joan et al. Análisis y gestión de políticas públicas. Barcelona: Planeta, 2012.
} 
POLÍTICAS HABITACIONAIS NACIONAIS:

OS DESAFIOS AO DIREITO DE MORADIA NOS ARRANJOS INSTITUCIONAIS DO PROGRAMA MINHA CASA MINHA VIDA Sergio Alexandre de Moraes Braga Junior

Para entender o diagnóstico principal atribuído por Boehm e Bohórquez, ${ }^{19}$ apresenta-se a relação triangular que existe entre as autoridades (governo), o agente regulador e o cliente (particular). Nessa relação, a assimetria de informação entre os atores é identificada como uma das principais causas de corrupção. Para tentar superar essa questão os autores nivelaram a assimetria de informação para enxergar as possibilidades de regulação em quatro níveis ou estágios.

No estudo das políticas públicas a percepção de ciclos, compreendidos como etapas ou fases, apresentam se desse modo, segundo Subirats ${ }^{20}$ e Schmidt: ${ }^{21}$ (i) definição do problema; (ii) inserção na agenda política; (iii) formulação; (iv) implementação e (v) avaliação.

Reduzir a assimetria de informação, nesse caso, como tema de estudo das fases, diz respeito a possibilitar o livre acesso da informação diminuindo a discricionariedade dos atores envolvidos e permitindo maior participação e uma prestação de contas efetiva. ${ }^{22}$

O Estado tem importância central nas ideias de North. ${ }^{23} \mathrm{Na}$ medida em que define e cuida do enforcement da base legal de uma sociedade, responde diretamente pela manutenção e formação de suas regras formais. Ao definir a estrutura de propriedade sobre o que é produzido, condiciona desde o início a performance das economias. A própria definição de Estado, para North, está umbilicalmente ligada à ideia de direitos sobre propriedade e regras de produção. ${ }^{24}$

\section{A MORADIA COMO DIREITO FUNDAMENTAL}

Instituída na Constituição Federal de 1988 como um direito fundamental à dignidade humana, a moradia constitui-se como uma peça-chave na construção de uma sociedade justa, com menos desigualdade e que se mostra preocupada em prover aos seus cidadãos condições minimamente necessárias ao seu pleno desenvolvimento, pois em seu texto o artigo $1^{\circ}$ inciso III a CF apresenta como um dos seus princípios fundamentais a dignidade da pessoa humana. Mais à frente, no capítulo II artigo $6^{\circ}$, estão elencados os direitos sociais como: a educação, a saúde, a alimentação, o trabalho, a moradia, o transporte, o lazer, a segurança, a previdência social, a proteção à maternidade e à infância, a assistência aos desamparados. ${ }^{25}$

Considerando o princípio da dignidade humana, bem como a democracia e direitos sociais, o conceito de moradia estende-se para além do simples fato de uma pessoa possuir um abrigo para o seu corpo; entende-se como o local onde se desenvolvem as relações humanas, reveste-se de um caráter social do qual o homem necessita como parte de valores de afirmação de sua importância como agente transformador do meio em que está inserido. Dessa forma:

Não possui apenas a conotação de habitação, mas envolve diretamente a qualidade de vida, dotada de condições adequadas de higiene e conforto, e que preserve a intimidade pessoal e a privacidade familiar. Em suma, requer uma habitação digna e adequada. ${ }^{26}$

\footnotetext{
${ }^{19}$ BOEHM, F.; BOHÓRQUEZ SUÁREZ, O. Anticorrupción en la regulación del servicio de suministro de agua potable: estudio de caso para Colombia. Opera, 11, p. 199-220, nov. 2011.

20 SUBIRATS, Joan et al. Análisis y gestión de políticas públicas. Barcelona: Planeta, 2012.

${ }^{21}$ SCHMIDT, João Pedro. Para estudar políticas públicas: aspectos conceituais, metodológicos e abordagens teóricas. Revista do Direito, Santa Cruz do Sul, v. 3, n. 56, jan. 2019.

22 BOEHM, F.; BOHÓRQUEZ SUÁREZ, O. Anticorrupción en la regulación del servicio de suministro de agua potable: estudio de caso para Colombia. Opera, 11, p. 199-220, nov. 2011.

${ }^{23}$ NORTH, Douglass. Instituições, mudança institucional e desempenho econômico. São Paulo: Três Estrelas, 2018.

${ }^{24}$ Id. Ibidem.

25 BRASIL. Constituição da República Federativa do Brasil. Disponível em: http://www.planalto.gov.br/ccivil_03/constituicao/constituicao. htm. Acesso em: 30 out. 2020.

${ }^{26}$ RANGEL, Helano Márcio Vieira; SILVA, Jacilene Veira. O direito fundamental à moradia como mínimo existencial e a sua efetivação à luz do Estatuto da Cidade. Disponível em: file:///C:/Users/CCE/Dropbox/My\%20PC\%20(DESKTOP-69HABGU)/Downloads/77-Texto\%20do\%20 Artigo-638-1-10-20110614\%20(1).pdf. Acesso em: 2 nov. 2020.
} 
A importância da moradia para a dignidade humana é um fenômeno que engloba dispositivos jurídicos internacionais, como preconiza a Declaração Universal dos Direitos Humanos de $1948,{ }^{27}$ o Pacto Internacional dos Direitos Econômicos, Sociais e Culturais (1996), Convenções sobre a Eliminação de todas as Formas de Discriminação Racial (1965); a Eliminação de Todas as Formas de Discriminação contra a Mulher (1979) e a Convenção sobre os Direitos das Crianças (1989). ${ }^{28}$

Diante deste cenário em que as necessidades humanas emergem como protagonistas das questões sociais, bem como o aumento das grandes cidades a partir do século 20, que culminou com o aumento de moradias insalubres e ocupações irregulares ${ }^{29}$ fazendo com que a sociedade civil compelisse o poder público a tomar algumas medidas para dirimir essas necessidades. Medidas essas materializadas quando foi sancionada a Lei $n^{\circ} 10.257 / 2001$ - O Estatuto da Cidade - como foi denominada, que regulamenta os artigos 182 e 183 da CF de 1988 e estabelece diretrizes gerais da política urbana. ${ }^{30}$

O Estatuto da Cidade configura-se como um avanço jurídico na instituição e regulamentação de políticas públicas em favor de moradias, bem como no âmbito ambiental, pois "(...) estabelece normas de ordem pública e interesse social que regulam o uso da propriedade urbana em prol do bem coletivo, da segurança e do bem-estar dos cidadãos, bem como do equilíbrio ambiental". ${ }^{31}$ Entende-se, dessa maneira, que as diretrizes elencadas na Lei pretendem garantir o direito social à moradia, como também reconhecem a função social da propriedade ao passo que se percebe uma preocupação com um meio ambiente ecologicamente equilibrado. ${ }^{32}$

"A implementação é a fase da execução, da concretização do que foi planejado na etapa da formulação," segundo Schmidt. ${ }^{33}$ As diretrizes contidas nos documentos de planos, políticas, projetos e programas visam a orientar a prática por meio de condutas e realizações que influem concretamente na vida dos cidadãos. ${ }^{34}$

Garantir o acesso da população em situação de vulnerabilidade social a uma moradia digna, em que se faça presente todo o aparato estatal para o efetivo uso de tal bem, como saneamento básico, acesso a transporte, unidade básica de saúde, escolas, segurança e lazer, configuram como grandes desafios a serem transpostos pelo poder público. Ademais, salienta-se que o Estatuto da Cidade traz consigo uma imposição de equilibrar as demandas sociais por moradia à proteção ambiental, pois não se trata apenas de colocar pessoas para habitar um local, tem de se considerar se este local é ecologicamente viável e sustentável. Percebe-se, dessa forma, que o Estatuto foi pensado em consonância com Constituição Federal, quando reafirma a dignidade humana como um dos parâmetros para a execução dos dispositivos jurídicos inclusivos, além de colocar a questão ambiental e sustentabilidade urbana atrelada a essa prática, algo que atualmente figura como importante debate no meio nacional e internacional.

\footnotetext{
${ }^{27}$ Art. XXV informa: "Toda pessoa tem direito a um padrão de vida capaz de assegurar a si e a sua família saúde e bem e bem-estar, inclusive alimentação, vestuário, habitação, cuidados médicos e os serviços sociais indispensáveis (...)" Declaração Universal dos Direitos Humanos. Disponível em: https://institutolegado.org/blog/declaracao-universal-dos-direitos-humanos-integra/?gclid=EAlalQobChMImau_1Yzj7AIVhYORCh2aEg1wEAAYAyAAEgId9_D_BwE. Acesso em: 1으ov. 2020.

${ }_{28}$ GONÇALVES, Fabiana Rodrigues. Direitos sociais: Direito à moradia. Disponível em: https://helberfreitas.jusbrasil.com.br/artigos/145423551/direitos-sociais-direito-a-moradia. Acesso em: 2 nov. 2020.

${ }_{29}$ SILVA, Daniela Madruga Rego Barros Victor; PEDROSO, Vanessa Alexsandra de Melo. A concretização do direito à moradia como direito fundamental social: Desafios do século XXI. p. 89. Disponível em: file:///C:/Users/CCE/Dropbox/My\%20PC\%20(DESKTOP-69HABGU)/ Downloads/a\%20concretização\%20do\%20direio\%20a\%20moradia.pdf. Acesso em: 2 nov. 2020.

${ }^{30}$ Lei $n^{\circ}$ 10.257, de 10 de julho de 2001. Disponível em: http://www.planalto.gov.br/ccivil_03/leis/leis_2001/l10257.htm. Acesso em: 2 nov. 2020.

${ }^{31}$ Parágrafo único. Lei $n^{\circ}$ 10.257/2001. Disponível em: http://www.planalto.gov.br/ccivil_03/leis/leis_2001/l10257.htm. Acesso em: 2 nov. 2020.

${ }^{32}$ Sobre o direito à propriedade subordinada ao cumprimento de sua função social, o Estatuto da Cidade regulamenta o artigo $182, \S 4^{\circ}$ que diz respeito às sanções urbanísticas e tributárias em terrenos subutilizados, a Usucapião Coletiva e a Concessão de uso especial para fins de moradia. ALFONSIN, Betânia. O Estatuto das Cidades sustentáveis, justas e democráticas. p. 313. Disponível em: http://www.periodicos.ulbra.br/index.php/direito/article/viewFile/2405/1640. Acesso em: 2 nov. 2020.

${ }_{33}$ SCHMIDT, João Pedro. Para estudar políticas públicas: aspectos conceituais, metodológicos e abordagens teóricas. Revista do Direito, Santa Cruz do Sul, v. 3, n. 56, jan. 2019.

${ }^{34}$ Id. Ibidem.
} 
Aliadas a esse contexto, as demandas sociais crescentes, frutos da urbanização das cidades, da procura por melhores empregos, transformaram o espaço geográfico quase que irreversivelmente, os locais que não deveriam ser habitados são reapropriados em moradias insalubres com risco iminente à vida. O poder público, por meio de seus gestores, mostra-se cada vez mais omisso quanto à resolução de tais necessidades e a partir disto, os movimentos de lutas em prol de moradia ganham cada vez mais espaço na sociedade, os quais buscam por meio da legislação legitimar suas possessões.

Partindo do viés do direito fundamental à moradia e à sustentabilidade urbana, pretende-se analisar o Estatuto da Cidade e as demandas sociais pelo direito à moradia digna e de que maneira o Estado atua como o viabilizador para suprir tais necessidades, bem como entender até que ponto o Estado pode ser responsabilizado nessas questões. A pesquisa se dará por meio de levantamento e análise bibliográfica sobre o tema, tendo a pesquisa um caráter qualitativo e a metodologia usada na pesquisa será a dedutiva.

\section{DIREITO À MORADIA E À SUSTENTABILIDADE URBANA: DESAFIOS, POSSIBILIDADES E APLICAÇÃO ÀS NECESSIDADES HUMANAS}

A Constituição Federal de 1988 coloca a dignidade humana como um dos seus princípios fundamentais, ${ }^{35}$ bem como estabelece como um dos seus objetivos erradicar a pobreza, a marginalização e reduzir as desigualdades sociais e regionais, ${ }^{36}$ o que nos permite entender que o texto constitucional, em sua essência, é voltado para o ser humano, fator que pode ser percebido quando o legislador tenta garantir que seja respeitado o mínimo a sua existência e que além disso, seja preservada a sua dignidade.

Colocada como um dos direitos fundamentais, a moradia aqui assume uma característica social, pois deixa de ser puramente patrimonial e passa a ter valor de necessidade básica, na medida em que se configura como o local de descanso, construção familiar e amparo. É a garantia do corpo e do intelecto.

Na vida cotidiana, porém, o que se percebe não é o que está descrito na Constituição Federal: a maior parte da população brasileira está submetida à extrema pobreza, à violência e à falta de políticas públicas de acesso a emprego, saúde e moradia, fatores considerados fundamentais na construção de uma sociedade mais igualitária.

Diante do exposto e entendendo a $\mathrm{CF} / 88$ como o instrumento jurídico de proteção ao indivíduo por excelência, seria natural recorrer a tal meio para obter o mínimo necessário para a sobrevivência. Mesmo, no entanto, que o texto afirme que é um direito do cidadão, isto não estimula o Estado a favorecer cada cidadão com uma habitação para morar, não no sentido literal da palavra, ${ }^{37}$ o que o Estado é obrigado a fazer é disponibilizar medidas e políticas públicas que viabilizem a aquisição de locais de moradias dignas para a sua população, bem como promover meios para que os administradores possam pôr em prática planos que diminuam o déficit habitacional.

Isso ocorre devido às limitações práticas, de cunho jurídico, econômico, político e social, no sentido de que, mesmo que os direitos fundamentais tenham efeito imediato, ${ }^{38}$ é preciso estabelecer os meios para que isso de fato aconteça, o que a caracteriza como uma lei programática, o que significa que: "As normas programáticas são aquelas destinadas a estabelecer determinados princípios ou fixar programas de ação para o poder público", 39 o que implica dizer que: "(...) são normas incompletas, isto é, não contemplam todos os elementos necessários para a sua formação, reclamando, para tanto, atividade legislativa ou administrativa complementar por meio de leis ou atos administrativos".

\footnotetext{
${ }^{35}$ BRASIL. Constituição da República Federativa do Brasil. Art.1ํ, inc. III Disponível em: http://www.planalto.gov.br/ccivil_03/constituicao/ constituicao.htm. Acesso em: 30 out. 2020.

${ }^{36}$ BRASIL. Constituição da República Federativa do Brasil. Art. 3o, inc. III. Disponível em: http://www.planalto.gov.br/ccivil_03/constituicao/ constituicao.htm. Acesso em: 30 out. 2020.

37 PERES, Tatiana Bonatti. Direito à moradia. Revista de Direito Privado, v. 42, p. 71-90, abr./jun. 2010. p. 4.

${ }^{38}$ BRASIL. Constituição da República Federativa do Brasil. Dos Direitos e garantias fundamentais. Art. 5ํ, §1ํ. Disponível em: https://www. senado.leg.br/atividade/const/con1988/con1988_15.12.2016/art_5_.asp. Acesso em: 8 nov. 2020.

39 PERES, Tatiana Bonatti apud. BARROSO, Luís Roberto. Direito à moradia. Revista de Direito Privado, v. 42, p. 71-90, p. 2, abr./jun. 2010.
} 
POLÍTICAS HABITACIONAIS NACIONAIS:

OS DESAFIOS AO DIREITO DE MORADIA NOS ARRANJOS INSTITUCIONAIS DO PROGRAMA MINHA CASA MINHA VIDA

Sergio Alexandre de Moraes Braga Junior

\section{Nesse sentido,}

a moradia constitui um dos direitos básicos para o usufruto dos outros direitos. A necessidade de abrigo é necessidade universal, de todos os povos, de todas as épocas da humanidade. Abrigar-se não só com objetivo de se proteger ou ter um teto para morar, abrigar-se para sentir-se digno de viver e realizar suas vontades e aspirações. A moradia é diferente de uma propriedade ou do direito de ser proprietário. Ao assegurar a moradia como um direito social, o que se busca é que o indivíduo titular deste direito possa ter um lar adequado para construir sua família, o seio da sociedade..$^{40}$

A partir desse entendimento, percebe-se que a legislação brasileira tem ao longo dos anos se empenhado em garantir esse direito. Pelo menos no plano jurídico o referido direito pode ser evocado quando das necessidades dos indivíduos mais carentes que são, justamente, os que mais reivindicam tal direito, pois essa é a única maneira de se posicionarem diante das desigualdades sociais que funcionam como um grande abismo em manter a dignidade de suas vidas. Nesse caso a lei, por ela mesma, não garante que o Estado suprirá tal necessidade, ela depende de ações concretas e de planos de ordem socioadministrativa para a sua efetivação.

A moradia é essencialmente social, seus preceitos se sobrepõem a outros direitos, como o de propriedade, está acima das questões econômicas e administrativas, considerando que tudo que se relaciona ao homem deve ser posto como prioridade. Dessa forma,

os direitos sociais são fruto de lutas históricas contra a opressão do homem pelo próprio homem, que culminou no Estado de Bem-Estar Social, tal Estado se coloca em franca oposição ao Estado Liberal, pois enquanto neste o que se espera é uma quase que total abstenção do Estado nos interesses particulares, naquele é fundamental a participação do Estado na vida dos cidadãos. Neste caso exige-se uma atuação positiva do Estado, que compreende não apenas a edição de leis ou mudanças constitucionais, mas a real e mais palpável concretização dos direitos fundamentais. ${ }^{41}$

Fica evidente que as medidas adotadas na Constituição Federal de 1988 colocam o homem e suas necessidades como algo central, o texto salvaguarda os direitos humanos, entende que o Estado tem de manter e fomentar políticas públicas com ações que sejam voltadas para o bem-estar da população. Se a nação é formada por seus cidadãos, logo suas diretrizes devem ser voltadas para atender as suas necessidades básicas, pois dessa forma os preceitos democráticos são garantidos e a desigualdade social amenizada. "Trata-se de um direito intimamente vinculado ao princípio da igualdade e à dignidade da pessoa humana, uma vez que ele proporciona condições básicas para a sobrevivência humana". ${ }^{42}$

Alguns pontos de acesso à moradia devem ser considerados: o acesso à terra urbana; acesso aos meios de produção; condições de aquisição da moradia e capacidade de suportar os custos da legalidade e segurança da moradia. ${ }^{43}$ Esses fatores, analisados à luz da efetivação do direito à moradia, muitas vezes podem ser vistos como entraves à sua prática, considerando a população de baixa renda, a qual não dispõe dos meios econômicos viáveis para arcar com as despesas que são impostas para adquirir um imóvel legalizado.

Assim entendido,

o que se percebe é que há uma notória e maléfica inversão na ordem natural de desenvolvimento de políticas públicas habitacionais, que ofende a racionalidade e prejudica a promoção de medidas voltadas à efetivação do direito à moradia. Em vez de seguir a ordem natural de planejar, construir a infraestrutura e em seguida, promover a ocupação de zonas urbanas, em boa parte dos casos o que ocorre é o inverso: primeiro a popula-

\footnotetext{
${ }_{40}$ PEREIRA, Uanderson. A efetividade dos direitos sociais. O direito social à moradia. Disponível em: http://www.puc-rio.br/pibic/relatorio_resumo2015/relatorios_pdf/ccs/DIR/DIR-Uanderson_Pereira.pdf. Acesso em: 20 nov. 2020.

${ }^{41}$ Ibidem, p. 5.

${ }^{42}$ ALÉCIO, Débora; FACHIN, Zulmar Antônio. O direito à moradia como instrumento de efetivação do princípio da igualdade. Disponível em: https://bu.furb.br/ojs/index.php/juridica/article/viewFile/8094/4441. Acesso em: 20 nov. 2020.

${ }^{43}$ MONTEIRO, Victor de Andrade. Fundamentalidade e efetividade do direito à moradia adequada. p. 92. Disponível em: http://www.repositorio.ufal.br/bitstream/riufal/5601/1/Fundamentalidade\%20e\%20efetividade\%20do\%20direito\%20humano\%20\%C3\%A0\%20moradia\%20adequada.pdf. Acesso em: 20 nov. 2020.
} 
POLÍTICAS HABITACIONAIS NACIONAIS:

OS DESAFIOS AO DIREITO DE MORADIA NOS ARRANJOS INSTITUCIONAIS DO PROGRAMA MINHA CASA MINHA VIDA

Sergio Alexandre de Moraes Braga Junior

ção ocupa áreas de forma precária, construindo casas à revelia de qualquer instrumento de planejamento, e, após isso, o Estado busca soluções para prover de alguma estrutura a ocupação irregular, tarefa essa que se mostra muito mais complexa, custosa e geralmente menos exitosa. ${ }^{44}$

Nesse sentido, Monteiro relata que se impõe, portanto, a compatibilização dos direitos individuais e coletivos com o desenvolvimento econômico e a preservação da natureza. Todos eles hábeis a garantir condições de vida digna, que somente será alcançada por meio de uma atuação tanto da sociedade quanto do poder público, voltada a um desenvolvimento sustentável, à medida que o direito à vida pressupõe o direito ao meio ambiente ecologicamente equilibrado e o próprio direito à cidade. ${ }^{45}$

No Brasil, a legislação caminhou em consonância com a tendência mundial, adotou leis que reforçam o discurso da proteção ambiental, colocando-a como elemento fundamental para a manutenção de uma vida digna, mas também como um dever da coletividade, ou seja, cabe aos cidadãos e gestores proteger o meio ambiente. Como bem assevera Monteiro:

As garantias de sustentabilidade passam por um rigoroso processo de integração e planejamento, cuja estruturação formal deve manifestar o dinamismo que existe no interior da sociedade e a seriedade das opções políticas que motivam os responsáveis pela sua proposição, organização e execução. A burocracia não pode servir como instrumento de construção de falsos argumentos ou ocultação de interesses com requintados recursos de retórica, especificamente da linguagem jurídica. ${ }^{46}$

Com o advento da preocupação com as causas ambientais tomando cada vez mais espaço das discussões sobre o futuro do planeta, a expressão "cidade sustentável" vem à tona como mais um elemento a ser pensado pelos gestores nos âmbitos nacional, estadual e municipal. Pensar em cidades sustentáveis não diz respeito apenas a preservar a natureza, mas sim propiciar ao cidadão condições e meios de viver bem e dignamente em um ambiente planejado, com estrutura material que supra minimamente as necessidades básicas, como saúde, lazer, transporte, saneamento básico, segurança, educação, entre outros. Assim,

desse conceito legal, entende-se que o termo cidade sustentável não significa somente a conservação e a recuperação dos recursos naturais, mas, sobretudo, a promoção de um planejamento territorial adequado às particularidades de cada município e a justa distribuição dos ônus e dos benefícios do processo de urbanização. (...) a sustentabilidade está ligada ao movimento da ecologia profunda, uma vez que não se separa o homem do ambiente como objeto isolado, mas sim, visualiza-se o mundo como uma rede de fenômenos interligados, no qual o homem é apenas um dos filamentos da teia da vida. Nessa nova forma de perceber as interconexões, desenvolve-se um pensamento sistêmico, em que as cidades, embora figurem como ecossistemas diferenciados dos ecossistemas naturais, são também um sistema vivo e interligado, fazendo parte do todo. ${ }^{47}$

\section{O ESTATUTO DA CIDADE COMO NORMATIZADOR DE UMA NOVA VISÃO DE URBANIZAÇÃO E CONSOLIDAÇÃO DO DIREITO À MORADIA}

No texto constitucional os artigos 182 e 183 estabelecem a política de desenvolvimento urbano, executada pelo poder público municipal em que ordena o pleno desenvolvimento das funções sociais das cidades e a usucapião dos imóveis até 250 metros quadrados, respectivamente. ${ }^{48} \mathrm{O}$ entendimento sobre as particularidades das cidades suscitou inúmeros debates e discussões acerca dos dispositivos legais e de que maneira a União, Estados e municípios agirão para efetivar positivamente o texto legal na sociedade. A partir destes debates foi aprovada a lei 10.257, de 10 de julho de 2001. Decorrida mais de uma década de embates políticos

\footnotetext{
${ }^{44}$ Ibidem, p. 94.

45 Ibidem, p. 122.

${ }^{46}$ Ibidem.

47 Ibidem apud, CAPRA, Fritjof, 2003.

${ }^{48}$ BRASIL. Constituição da República Federativa do Brasil. Artigos 182 e 183. Disponível em: https://www.senado.leg.br/atividade/const/ con1988/con1988_07.05.2020/art_183_.asp\#: :text=183\&text=Da\%20Pol\%C3\%Adtica\%20Urbana-,Art.,outro\%20im\%C3\%B3vel\%20urbano\%20ou\%20rural. Acesso em: $2 \overline{7}$ nov. 2020.
} 
POLÍTICAS HABITACIONAIS NACIONAIS:

e sociais, o Estatuto da Cidade, como ficou conhecida a lei, foi aprovada, estabelecendo a regulamentação dos artigos 182 e 183 da Constituição Federal.

A partir deste momento, que pode ser entendido como o marco regulador das diretrizes urbanísticas brasileiras, a regulamentação das cidades em todo o território tinha uma lei à qual os gestores e indivíduos da sociedade civil podem aludir em prol do desenvolvimento urbano. A referida lei significa um grande avanço não apenas no plano prático, no sentido da maneira como as cidades devem ser formadas, mas na maneira como ratifica o caráter social da moradia e das cidades e também na questão do desenvolvimento sustentável das áreas urbanas, legando às gerações futuras um ambiente ecologicamente protegido.

Como bem explicita o seu parágrafo único “ (...) estabelece normas de ordem pública e interesse social que regulam o uso da propriedade urbana em prol do bem coletivo, da segurança e do bem-estar dos cidadãos, bem como do equilíbrio ambiental". ${ }^{49}$ Ainda no mesmo texto:

Art. 20 A política urbana tem por objetivo ordenar o pleno desenvolvimento das funções sociais da cidade e da propriedade urbana, mediante as seguintes diretrizes gerais:

I - garantia do direito a cidades sustentáveis, entendido como o direito à terra urbana, à moradia, ao saneamento ambiental, à infraestrutura urbana, ao transporte e aos serviços públicos, ao trabalho e ao lazer, para as presentes e futuras gerações;

II - gestão democrática por meio da participação da população e de associações representativas dos vários segmentos da comunidade na formulação, execução e acompanhamento de planos, programas e projetos de desenvolvimento urbano..$^{50}$

Fica clara a preservação do princípio da função social da propriedade no Estatuto da Cidade, o qual pode ser interpretado como o reconhecimento da função da propriedade em benefício da sociedade como um todo. Outro fator importante é a gestão democrática, a ênfase na participação da sociedade civil; esta nova concepção de administração pública coloca o cidadão como um gestor, um colaborador e fiscalizador dos projetos que irão incidir sobre sua vida. A cidade, considerada um organismo em transformação, deve ser pensada e planejada com a participação em conjunto dos gestores públicos e com representantes da sociedade civil, com o objetivo de garantir que as decisões tomadas passem pelas esferas políticas, administrativas e sociais.

Para que isto seja possível o Estatuto prevê os seguintes ditames:

Art. 43 Para garantir a gestão democrática da cidade, deverão ser utilizados, entre outros, os seguintes instrumentos:

I - órgãos colegiados de política urbana, nos níveis nacional, estadual e municipal;

II - debates, audiências e consultas públicas;

III - conferências sobre assuntos de interesse urbano, nos níveis nacional, estadual e municipal;

IV - iniciativa popular de projeto de lei e de planos, programas e projetos de desenvolvimento urbano. ${ }^{51}$

Esse sistema de participação democrática vincula-se ao princípio democrático da Constituição Federal, ${ }^{52}$ incumbindo a todos os setores a responsabilidade e o direito de construção social. Percebe-se que em termos de instrumentos jurídicos, o Estado garante que as decisões sejam tomadas após plena participação popular, pois as decisões devem partir da sociedade, devem atender as suas necessidades e os gestores públicos estão sujeitos a essas diretrizes.

\footnotetext{
${ }^{49}$ BRASIL. Lei 10.257 de 10 de julho de 2001. Parágrafo único. Disponível em: http://www.planalto.gov.br/ccivil_03/LEIS/LEIS_2001/L10257. htm. Acesso em: 27 nov. 2020.

50 Ibidem, art. 20, incisos I, II.

${ }^{51}$ Idem, art. 43, incisos I, II.

52 "Todo poder emana do povo, que o exerce por meio de representantes eleitos ou diretamente, nos termos desta Constituição". BRASIL. Constituição da República Federativa do Brasil. Parágrafo único. Disponível em: http://www.planalto.gov.br/ccivil_03/constituicao/constituicao.htm. Acesso em: 27 nov. 2020.
} 
Nesse sentido, o Estatuto da Cidade trouxe instrumentos jurídicos que promovem a preservação ambiental e avança nas questões que abarcam a relação homem e natureza, isto por que a lei está relacionada com a função social do uso da propriedade, além de inovar na questão sobre a forma de uso e ocupação do solo, estabelece a participação do cidadão nas decisões sobre o destino da cidade e amplia a possibilidade de regulação das posses urbanas.

Segundo Souza, o Estatuto da Cidade vem ao encontro da necessidade de regular tal relação, de forma que nossas cidades sejam um espaço ambientalmente sustentável. Com o desenvolvimento urbano sustentável nasce a importância da execução de uma política urbana eficaz, capaz de frear o crescimento globalizado descontrolado, capitalista e político, que sempre atingiu interesses da minoria da população, as normas de ordem pública e interesse social que regulam o uso da propriedade urbana em prol do bem coletivo, da segurança e do bem-estar dos cidadãos, bem como do equilíbrio ambiental. ${ }^{53}$

\section{CIDADE ILEGAL E EXCLUSÃO SOCIAL}

O processo de urbanização das cidades brasileiras ocorreu de forma rápida e de desordenada a partir da primeira metade do século 20 , ocasião em que o país deixava de ser essencialmente agrário e passava a ser urbano e industrial. Esse crescimento deu-se pelo êxodo rural e pelo fato de que as cidades ofereciam melhores oportunidades de emprego e renda a uma massa populacional que via nas cidades uma oportunidade de mudança de status social. ${ }^{54}$

Falar em cidades planejadas implica reconhecer que existe, paralela a esta, uma cidade que cresce de maneira desordenada e alheia à recomendação judicial: trata-se da cidade ilegal. Esta surge em consequência da ausência do Estado em prover moradias, bem como coibir a propagação de ocupações em áreas de risco que não dispõem de infraestrutura habitacional, pelo contrário, é nesses espaços que fica evidenciado o quanto a falta de políticas públicas e planejamento urbano favorecem a desigualdade social e marginalização das pessoas que vivem ali.

A cidade, neste sentido, é entendida como o centro das ações políticas que envolvem os indivíduos que nela habitam, é o palco onde se desdobram as lutas e exigências por melhores condições de vida. Então,

a cidade assume a condição de espaço coletivo culturalmente rico e diversificado que pertence a todos os seus habitantes, onde o usufruto coletivo da riqueza, bens e conhecimentos são garantidos a todos. O seu território é lugar de exercício e cumprimento dos direitos difusos e a sua gestão se dá de forma democrática e coletiva. ${ }^{55}$

Embora o crescimento das cidades e o aumento das demandas habitacionais sinalizassem aos governantes a urgência de se pensar nos espaços urbanos, ao longo da História brasileira não foi isso que aconteceu, o que se processou foi o adensamento da população mais pobre em áreas periféricas, desprovidas de estruturas, nas quais o que se percebe é a falta de vontade política em planejar as cidades para atender às demandas populacionais. Ainda que o crescimento seja exponencial é dever do Estado buscar melhorias a fim de prover as necessidades de seus habitantes. ${ }^{56}$

A expressão "cidade ilegal" não está vinculada ao sentido de infração, de fora da lei ou que existe um espaço que geograficamente está contrário à lei, mas apenas de esta figurar fora da lógica do mercado imobiliário privado e a subordinação do Estado a isto. São áreas desvalorizadas, sem infraestrutura, que são ocupadas pela população mais carente e muitas vezes sujeitas a catástrofes ambientais e negligenciadas pela administração pública. ${ }^{57}$

\footnotetext{
${ }^{53}$ SOUZA, Marcos Felipe Alonso de. O meio ambiente urbano em face do Estatuto da Cidade: importância e implicações da lei 10.257/01para as sociedades urbanas. Disponível em: http://www.cognitiojuris.com/artigos/03/06.html. Acesso em: 28 nov. 2020.

54 LUCENA, Felipe Campos; SILVA, Maria Eliza Lemos Schueller Pereira. O direito à cidade sustentável como direito fundamental. Disponível em http://www.publicadireito.com.br/conpedi/manaus/arquivos/anais/brasilia/07_814.pdf. Acesso em: 24 nov. 2020.

55 LUCENA, Felipe Campos; SILVA, Maria Eliza Lemos Schueller Pereira. O direito à cidade sustentável como direito fundamental. Disponível em: http://www.publicadireito.com.br/conpedi/manaus/arquivos/anais/brasilia/07_814.pdf. Acesso em: 24 nov. 2020.

${ }^{56}$ Idem, p. 3.

57 STEFANIAK, João Luiz; STEFANIAK, Jeaneth Nunes. 2018. A cidade ilegal e o Estatuto da Cidade: análise da efetividade dos instrumentos de regularização fundiária. Disponível em: file:///C:/Users/CCE/Dropbox/My\%20PC\%20(DESKTOP-69HABGU)/Downloads/2543-Texto\%20 do\%20artigo-14375-1-10-20120613\%20(1).pdf. Acesso em: 29 nov. 2020.
} 
POLÍTICAS HABITACIONAIS NACIONAIS:

OS DESAFIOS AO DIREITO DE MORADIA NOS ARRANJOS INSTITUCIONAIS DO PROGRAMA MINHA CASA MINHA VIDA

Sergio Alexandre de Moraes Braga Junior

Nesse entendimento, é possível relacionar a miséria e a violência à falta de cumprimento dos direitos fundamentais, e entre esses direitos está a moradia. A gestão das políticas urbanas das cidades brasileiras ainda é voltada para aqueles que possuem algum tipo de renda, de ganho mensal, está longe de ser totalmente democrática. Digamos que a democracia está em promover a todos os cidadãos brasileiros oportunidades iguais, mas que ainda não alcançamos tal princípio. Daí entende-se que

a sociedade contemporânea tem seus valores voltados para o progresso e o trabalho, logo, as pessoas que não possuem capacidade ou possibilidade de participar do mercado de trabalho formal são vistas como excluídas. Nesta perspectiva, a pobreza surge como sinônimo da incapacidade de participar do mercado de consumo, enquanto que o desemprego aparece como a falta de capacidade de participar da atividade laboral, sendo esses elementos considerados desencadeadores de exclusão. ${ }^{58}$

A partir dessa perspectiva, está um lado o Estado que se omite nas questões em que deveria atuar para combater a miséria e não o faz, e do outro está uma massa populacional que devido à falta de oportunidade ficou empobrecida e uma das consequências é a ocupação de áreas de risco ou de proteção ambiental, pois é neste lugar que muitos são obrigados a morar, devido à falta de condições mínimas de pagar outro lugar para viver. Assim, segundo Catão, a questão da exclusão social atual é bem mais problemática, possuindo, além dos elementos econômico e político, o social e o simbólico. Nesse contexto, atualmente a exclusão tem uma dimensão de descolamento, pois enquanto a parte integrada continua desempenhando suas atividades regularmente, a desintegrada (os excluídos) é alijada e rechaçada. Então, a exclusão social pode ser analisada por meio de um fenômeno que vem acontecendo no decorrer do tempo, com os processos sociais de evolução, dualização e segregação; ou pode ser também considerado um mecanismo complexo e contraditório que contém, em si mesmo, a inclusão e a exclusão ${ }^{59}$.

\section{OS MOVIMENTOS SOCIAIS PELA LUTA DO DIREITO À MORADIA E A RESPONSABILIDADE DO ESTADO}

O fenômeno da urbanização das cidades trouxe consigo inúmeros problemas sociais advindos da falta de estrutura básica dos centros urbanos, com uma população crescendo de forma vertiginosa e a lentidão dos gestores públicos em planejar os espaços, pensar e pôr em prática projetos voltados para a questão urbanísti$\mathrm{ca}$, que englobe a população e o meio ambiente de maneira integrada. Essa falta de planejamento dos gestores resulta na ocupação de áreas de risco ou de preservação ambiental por parte da população que não possui os meios financeiros para habitar um imóvel em um lugar adequado.

As chamadas ocupações de risco fazem parte do cotidiano dos centros urbanos brasileiros. É uma realidade que está inserida na paisagem das cidades e altera o equilíbrio do meio ambiente ao seu redor, mas é o meio pelo qual a população encontrou para fazer valer seu direito fundamental à moradia. Esse processo não é recente e os gestores pouco se empenharam em resolver. Dessa forma,

(...) as cidades brasileiras, no início e meados do século passado, não estavam preparadas para o crescimento desenfreado que viriam a experimentar, de forma que o Estado não possuía políticas públicas que contribuíssem na promoção de moradias adequadas para a grande parcela da população que se encontrava em situação de vulnerabilidade social e econômica. Devido a isso, muitas pessoas acabaram se dirigindo para espaços precários, inadequados para ocupação humana, de grande risco ambiental, por não possuírem poder aquisitivo (condições econômicas viáveis) para se instalarem em lugares com condições de moradia adequadas. ${ }^{60}$

\footnotetext{
${ }^{58}$ CATÃO, Marconi do Ó. A exclusão social e as favelas na cidades do Rio de Janeiro. Disponível em: file:///C:/Users/CCE/Dropbox/My\%20 PC\%20(DESKTOP-69HABGU)/Downloads/18839-63484-1-PB.pdf. Acesso em: 29 nov. 2020.

59 Ibidem, p. 1.012.

${ }^{60}$ FORTUNATO, Bruna; SCHONARDIE, Elenise Felzke. Ocupações irregulares: conflitos entre o direito à moradia e a responsabilidade civil do Estado por danos ambientais. Disponível em: file:///C:/Users/CCE/Dropbox/My\%20PC\%20(DESKTOP-69HABGU)/Downloads/4079-Texto\%20do\%20artigo-25095-1-10-20160217.pdf. Acesso em: 29 nov. 2020.
} 
POLÍTICAS HABITACIONAIS NACIONAIS:

OS DESAFIOS AO DIREITO DE MORADIA NOS ARRANJOS INSTITUCIONAIS DO PROGRAMA MINHA CASA MINHA VIDA

Sergio Alexandre de Moraes Braga Junior

A falta de moradia é um problema recorrente no país deste o seu processo de industrialização, acentuado a partir do século 20. O Estado tentou promover o acesso da população de baixa renda à moradia por meio de medidas como a Fundação Casa Popular, lançado em 1946 e que financiava habitações, mas se mostrou insuficiente; depois durante o período ditatorial com a criação de habitações, mas que beneficiaram apenas as classes média e alta. ${ }^{61}$ Diante desses fatos, percebe-se que as políticas adotadas pelo Estado eram insuficientes para suprir as necessidades populacionais.

A partir daí as áreas de preservação ambiental ou espaços verdes no entorno das cidades passaram a ser sistematicamente ocupados por essas famílias que não dispõem de meios financeiros para residir em locais com infraestrutura, terminam por viverem com riscos iminentes a sua saúde e vida, expondo-se a perigos de desastres constantes e sem os aparatos necessários à sua dignidade.

Igualmente precárias e com riscos à saúde e vida, são as ocupações irregulares nos centros urbanos, em que grupos de desabrigado invadem imóveis abandonados. Para Fortunato e Schonardie, outra alternativa encontrada pelos sujeitos excluídos, sem acesso a uma moradia digna, é ocupar prédios abandonados nos próprios centros das cidades, locais desamparados, largados pelo poder público, nos quais a desordem e a criminalidade se instalam de forma "confortável". Ou então esses sujeitos excluídos sublocam tais espaços que possuem acesso à água, energia elétrica, coleta de lixo e esgoto (dando a sensação de pertencerem à cidade legal). Esses espaços muitas vezes chamados de becos ou de cortiços não possuem condições de salubridade e segurança. Outra questão é que a qualquer momento esses sujeitos podem sofrer ações de despejo, resultando em indivíduos sem moradia e com seus direitos fundamentais violados. ${ }^{62}$

Considerando tais afirmações, e pensando em uma possível responsabilização do Estado diante da omissão em prover os meios pelos quais o cidadão possa adquirir um lugar digno para constituir família, bem com as consequências negativa que podem sobrevir àqueles sujeitos locados em áreas de risco, observa-se o artigo 37 parágrafo 6o da Constituição Federal de 1988, em que destaca que se um dano ocorre devido a uma ação ou omissão de um agente do Estado, este deverá responder independentemente de culpa. ${ }^{63}$

Diante dos projetos desenvolvidos pelo Programa de Aceleração e Crescimento - PAC - teremos a verificação de problemas existentes devido à falta de análise de territórios e regiões, os chamados territórios cegos, permitindo a execução do projeto sem que antes houvesse uma prévia análise real e efetiva para a conclusão daquela obra, visto que impactos negativos irão causar atrasos e um maior custo. ${ }^{64}$

Lotta e Favaretto ${ }^{65}$ afirmam que existe uma grande restrição quanto aos projetos de intersetorialidade no caso do PAC, e que a coordenação intersetorial deveria ser realizada no momento do planejamento e concretização das obras. Quando essa coordenação consegue ser efetivada, ocorrem os mecanismos de rede que proporcionam um ambiente favorável aos compartilhamentos de ideias e objetivos, em sistema de enforcement.

A localização dos empreendimentos sempre foi motivo de questionamentos. A incorporação da faixa de zero a três salários mínimos entre os beneficiados do PMCMV trouxe novas exigências necessárias à resolução de problemas operacionais daí decorrentes, tais como preços elevados dos terrenos disponíveis para construção de moradias com valor acessível a essa população e a consequente dificuldade de localização dos empreendimentos em regiões com infraestrutura urbana. Exigiu, também, maior controle por parte dos órgãos públicos para garantir normas mínimas de qualidade arquitetônica das moradias. ${ }^{66}$

\footnotetext{
${ }^{61}$ Ibidem, p. 193.

62 Idem, p. 195.

${ }^{63}$ FORTUNATO, Bruna; SCHONARDIE, Elenise Felzke. Ocupações irregulares: conflitos entre o direito à moradia e a responsabilidade civil do Estado por danos ambientais. p. 198. Disponível em: file://C:/Users/CCE/Dropbox/My\%20PC\%20(DESKTOP-69HABGU)/Downloads/ 4079-Texto\%20do\%20artigo-25095-1-10-20160217.pdf. Acesso em: 29 nov. 2020.

${ }^{64}$ LOTTA, Gabriela; FAVARETTO, Arilson. Os arranjos institucionais dos investimentos em infraestrutura no Brasil: uma análise sobre seis grandes projetos do Programa de Aceleração de Crescimento. Texto para Discussão Ipea, 2.253, nov. 2016.

${ }^{65}$ LOTTA, Gabriela; FAVARETTO, Arilson. Os arranjos institucionais dos investimentos em infraestrutura no brasil: uma análise sobre seis grandes projetos do Programa de Aceleração de Crescimento. Texto para Discussão Ipea, 2.253, nov. 2016.

${ }^{66}$ LOUREIRO, Maria Rita; MACÁRIO, Vinícius; GUERRA, Pedro Henrique. Legitimidade e efetividade em arranjos institucionais de políticas públicas: o Programa Minha Casa Minha Vida, Rev. Adm. Pública. Rio de Janeiro, 49(6), p. 1.531-1.554, nov./dez. 2015.
} 
POLÍTICAS HABITACIONAIS NACIONAIS:

OS DESAFIOS AO DIREITO DE MORADIA NOS ARRANJOS INSTITUCIONAIS DO PROGRAMA MINHA CASA MINHA VIDA

Sergio Alexandre de Moraes Braga Junior

Os déficits de legitimidade democrática nos arranjos institucionais do PMCMV são constantemente levantados ${ }^{67} \mathrm{Em}$ vários fóruns e em sites na Internet, os movimentos sociais participantes desses colegiados revelaram preocupação com problemas contidos no desenho do programa, declarando que a construção das unidades precisava estar associada à política urbana que garantisse o acesso a serviços públicos, como saúde, educação, transporte, uma vez que eles receavam que fosse repetida a experiência dos conjuntos habitacionais do período do Banco Nacional de Habitação - BNH. Também urbanistas e profissionais ligados ao Instituto de Arquitetos do Brasil (IAB) afirmam sua escassa articulação com o planejamento urbano e apontam a ausência de mecanismos institucionais e incentivos para financiamento de reformas de moradias subutilizadas.

\section{CONSIDERAÇÕES FINAIS}

O direito à moradia explicitado na Constituição Federal de 1988, entendido como um direito social e fundamental à dignidade humana, configura-se como um dos elementos essenciais para a efetivação do Estado Democrático de Direito, considerando que este, ao prover os meios pelos quais cada indivíduo possa obter sua moradia, fará com que toda a sociedade se desenvolva, pois entende-se que ao possuir um local digno para viver, cada cidadão estará social e psicologicamente preparado para desenvolver todas as suas potencialidades perante o Estado.

A garantia do direito à moradia não gera ao Estado a obrigação de prover uma moradia para cada cidadão; na realidade o entendimento se dá pela obrigação do Estado de prover os meios pelos quais cada indivíduo possa, por seus próprios meios, adquirir um local digno para morar. Para que isto seja possível, a União deve promover políticas públicas que envolvam os Estados e municípios a fim de possibilitar a construção de cidades sustentáveis.

Entende-se que assegurar moradias dignas aos cidadãos significa prover aos sujeitos locais de habitação com todo o aparato urbanístico que se espera do poder público, como lazer, segurança, saúde, educação, transporte, acessibilidade, trabalho, etc. São estruturas mínimas que dão dignidade para quem mora na região, haja vista que se entende que sem elas, residir em tal localidade torna-se inviável.

As metas construtivas estabelecidas foram alcançadas e até mesmo superaram os ideais iniciais, pois o PMCMV foi incorporado ao PAC, tornando-se prioritário na agenda governamental. Como se mencionou, isso significou, de um lado, que o programa não seria passível de contingenciamento de recursos orçamentários e, de outro, que ele seria objeto de procedimentos especiais de gestão e monitoramento.

Esse arranjo institucional, todavia, não se mostrou politicamente legitimador, na medida em que atores sociais relevantes na área, como os movimentos populares e os grupos organizados de especialistas em temas urbanos, não têm tido suas demandas contempladas.

O PMCMV está orientado pela lógica empresarial e econômica de curto prazo e não inserido em uma política efetivamente estrutural de planejamento e de reforma urbana que, mesmo exigindo uma perspectiva temporal de longo prazo, é indispensável para melhorar a qualidade de vida nas cidades, como reivindicam os especialistas da área e grupos sociais envolvidos.

Nesse planejamento entra o conceito de cidade sustentável, que deve ser pensada de maneira a garantir toda a infraestrutura para a moradia da população, mas deve ser planejada visando às gerações futuras e à preservação do meio ambiente, uma cidade sustentável existe como um organismo vivo interagindo entre meio ambiente e pessoas.

Desde a Constituição de 1988 o Estado tem avançado juridicamente para que os preceitos legais não sejam apenas letra, e sim algo concreto que possa ser aplicado à vida dos cidadãos. O que se percebe, no entanto, é um avanço tímido, que não acompanha as dinâmicas sociais urbanas, a cidade cresce muito rápido e os gestores públicos não conseguem consolidar o texto constitucional. A alegação é quase sempre a mesma: as dificuldades econômicas, que são usadas como justificativas para a falta de planejamento e descaso com os mais humildes.

${ }^{67}$ LOUREIRO, Maria Rita; MACÁRIO, Vinícius; GUERRA, Pedro Henrique. Legitimidade e efetividade em arranjos institucionais de políticas públicas: o Programa Minha Casa Minha Vida. Rev. Adm. Pública, Rio de Janeiro, 49(6), p. 1.531-1.554, nov./dez. 2015. 
POLÍTICAS HABITACIONAIS NACIONAIS:

Assim, entende-se que para a concretização do direito à moradia na sociedade, espera-se do Estado uma postura mais enérgica quanto à efetivação dos preceitos legais, como também a exigir de Estados e municípios que ajam em conjunto com a esfera federal a fim de adquirir recursos que possam ser usados para que cidades sustentáveis possam sair do papel e, dessa forma, garantir que os preceitos constitucionais possam ser efetivados.

\section{REFERÊNCIAS}

ALÉCIO, Débora; FACHIN, Zulmar Antônio. O direito à moradia como instrumento de efetivação do princípio da igualdade. Disponível em: https://bu.furb.br/ojs/index.php/juridica/article/viewFile/8094/4441. Acesso em: 20 nov. 2020.

ALFONSIN, Betânia. O Estatuto das Cidades sustentáveis, justas e democráticas. Disponível em: http://www.periodicos.ulbra. br/index.php/direito/article/viewFile/2405/1640. Acesso em: 2 nov. 2020.

ANDRADE, Danilo. Políticas públicas: O que são e para que servem? Disponível em: https://www.politize.com.br/politicas-publicas/\#: :text=Conforme\%20defini\%C3\%A7\%C3\%A30\%20corrente\%2C\%20pol\%C3\%ADticas\%20p\%C3\%BAblicas,grupos\%20da\%20sociedade\%20ou\%20para. Acesso em: 4 fev. 2016.

BARROSO, Luís Roberto. Direito à moradia. Revista de Direito Privado, v. 42, p. 71-90, p. 2, abr./jun. 2010.

BERTOLDI, Márcia Rodrigues; OLIVEIRA, Olga Maria Boschi Aguiar de. Manual metodológico para o projeto de pesquisa em direito. Disponível em: https://wp.ufpel.edu.br/ppgd/files/2019/10/Manual-Projeto-de-Pesquisa-vers\%C3\%A3o-final.pdf. Acesso em: 10 dez. 2020.

BOEHM, F.; BOHÓRQUEZ SUÁREZ, O. Anticorrupción en la regulación del servicio de suministro de agua potable: estudio de caso para Colombia. Opera, 11, p. 199-220, nov. 2011.

BRASIL. Constituição da República Federativa do Brasil. Disponível em: http://www.planalto.gov.br/ccivil_03/constituicao/ constituicao.htm. Acesso em: 27 nov. 2020.

BRASIL. Lei $n^{\circ}$ 10.257, de 10 de julho de 2001. Disponível em: http://www.planalto.gov.br/ccivil_03/leis/leis_2001/I10257.htm. Acesso em: 2 nov. 2020.

BUCCI, Maria Paula Dallari (org.). Políticas públicas - reflexões sobre o conceito jurídico. São Paulo: Saraiva, 2006.

CAPRA, Fritjof. As conexões ocultas. Idesa: São Paulo, 2003.

CATÃO, Marconi do Ó. A exclusão social e as favelas na cidade do Rio de Janeiro. Disponível em: file:///C:/Users/CCE/Dropbox/ My\%20PC\%20(DESKTOP-69HABGU)/Downloads/18839-63484-1-PB.pdf. Acesso em: 29 nov. 2020.

COSTA, Beatriz Souza; VENÂNCIO, Stephanie Rodrigues. A função social da cidade e o direito à moradia digna como pressupostos do desenvolvimento urbano sustentável. p. 121-122. Disponível em: file:///C:/Users/CCE/Dropbox/My\%20PC\%20(DESKTOP-69HABGU)/ Downloads/ 3481-17523-1-PB\%20(1).pdf. Acesso em: 15 nov. 2020.

FIGUEIREDO, Argelina; LIMONGI, Fernando. Mudança constitucional, desempenho do legislativo e consolidação institucional. In: FIGUEIREDO, Argelina; LIMONGI, Fernando. Executivo e legislativo na nova ordem constitucional. 2. ed. Rio de Janeiro: FGV, 1999. p. 41-72. Cap. 2.

FLORISSE, Elena. Desenvolvimento urbano sustentável: um estudo sobre sistemas de indicadores de sustentabilidade urbana. p. 28. Disponível em: https://repositorio.ufpe.br/bitstream/123456789/3211/1/arquivo2355_1.pdf. Acesso em: 19 nov. 2020.

FLYVBJERG, Bent; BRUZELIUS, Nils; ROTHENGATTER, Werner. Megaprojects and risk: an anatomy of ambition. Cambridge: Cambridge University Press, 2003.

FORTUNATO, Bruna; SCHONARDIE, Elenise Felzke. Ocupações irregulares: conflitos entre o direito à moradia e a responsabilidade civil do Estado por danos ambientais. Disponível em: file:///C:/Users/CCE/Dropbox/My\%20PC\%20(DESKTOP-69HABGU)/ Downloads/4079-Texto\%20do\%20artigo-25095-1-10-20160217.pdf. Acesso em: 29 nov. 2020.

GOMES, Daniela; ZAMBAM, Neuro José. O desafio da sustentabilidade urbana. Disponível em: https://seer.imed.edu.br/index. php/revistadedireito/article/view/256/987. Acesso em: 19 nov. 2020.

GONÇALVES, Fabiana Rodrigues. Direitos sociais: direito à moradia. Disponível em: https://helberfreitas.jusbrasil.com.br/ artigos/145423551/direitos-sociais-direito-a-moradia. Acesso em: 2 nov. 2020.

HOCHMAN, Gilberto, ARRETCHE, Marta e MARQUES, Eduardo (org.). Políticas públicas no Brasil. Rio de Janeiro: Editora Fiocruz, 2007.

IMMERGUT, Ellen M. As regras do jogo: a lógica da política de saúde na França, na Suíça e na Suécia. Revista Brasileira de Ciências Sociais, n. 30, a. 11, fev. 1996.

KINGDON, John W. Agendas, Alternatives, and Public Policies. 2. ed. Nova York: Harper Collins College Publishers, 1995.

KINGDON, John. Como chega a hora de uma idéia? In: SARAVIA, Enrique; FERRAREZI, Elisabete (org.). Políticas públicas. Brasília: Enap, 2006. 
POLÍTICAS HABITACIONAIS NACIONAIS:

LIMONGI, Fernando; FIGUEIREDO, Argelina. Processo orçamentário e comportamento Legislativo: emendas individuais, apoio ao Executivo e programas de governo. Dados - Revista de Ciências Sociais, Rio de Janeiro, v. 48, n. 4, p. 737-776, 2005.

LOTTA, Gabriela; FAVARETTO, Arilson. Os arranjos institucionais dos investimentos em infraestrutura no Brasil: uma análise sobre seis grandes projetos do Programa de Aceleração de Crescimento. Texto para Discussão Ipea, 2.253, nov. 2016.

LOUREIRO, Maria Rita; MACÁRIO, Vinícius; GUERRA, Pedro Henrique. Legitimidade e efetividade em arranjos institucionais de políticas públicas: o Programa Minha Casa Minha Vida. Rev. Adm. Pública, Rio de Janeiro, 49(6), p. 1.531-1.554, nov./dez. 2015.

LUCENA, Felipe Campos; SILVA, Maria Eliza Lemos Schueller Pereira. O direito à cidade sustentável como direito fundamental. Disponível em: http://www.publicadireito.com.br/conpedi/manaus/arquivos/anais/brasilia/07_814.pdf. Acesso em: 24 nov. 2020.

MARQUES, Eduardo. Notas críticas à literatura sobre Estado, políticas estatais e atores políticos. BIB, Rio de Janeiro, n. 43, 10 semestre de 1997.

MENICUCCI, Telma M. G. A implementação da reforma sanitária: a formação de uma política. Saúde e Sociedade, São Paulo, v. 15, n. 2, maio/ago. 2006.

MENY, Yves; THOENIG, Jean-Claude. Las políticas públicas. Barcelona: Ariel, 1992.

MONTEIRO, Victor de Andrade. Fundamentalidade e efetividade do direito à moradia adequada. p. 92. Disponível em: http:// www.repositorio.ufal.br/bitstream/riufal/5601/1/Fundamentalidade\%20e\%20efetividade\%20do\%20direito\%20humano\%20 \%C3\%A0\%20moradia\%20adequada.pdf. Acesso em: 20 nov. 2020.

MOREIRA, Thiago de Miranda Queiroz. Disputas institucionais e interesses corporativos no sistema de justiça: impasses na criação da Defensoria Pública nos Estados. Dados, Rio de Janeiro, v. 62, n. 4, e20170071, 2019.

NORTH, Douglass. Instituições, mudança institucional e desempenho econômico. São Paulo: Três Estrelas, 2018.

PEREIRA, Uanderson. A efetividade dos direitos sociais. O direito social à moradia. Disponível em: http://www.puc-rio.br/pibic/ relatorio_resumo2015/relatorios_pdf/ccs/DIR/DIR-Uanderson_Pereira.pdf. Acesso em: 20 nov. 2020.

PERES, Tatiana Bonatti. Direito à moradia. Revista de Direito Privado, v. 42, p. 71-90, abr./jun, 2010. p. 4.

PIRES, Roberto; GOMIDE, Alexandre. Governança e capacidades estatais: uma análise comparativa de programas federais. Rev. Sociol. Polit., v. 24, n. 58, p. 121-143, jun. 2016.

PIRES, Roberto et al. Burocracia e políticas públicas no Brasil: interseções analíticas. Brasília: Ipea; Enap, 2018.413 p.

RANGEL, Helano Márcio Vieira; SILVA, Jacilene Veira. O direito fundamental à moradia como mínimo existencial e a sua efetivação à luz do Estatuto da Cidade. Disponível em: file://C:/Users/CCE/Dropbox/My\%20PC\%20(DESKTOP-69HABGU)/Downloads/77-Texto\%20do\%20Artigo-638-1-10-20110614\%20(1).pdf. Acesso em: 2 nov. 2020.

SCHMIDT, João Pedro. Para estudar políticas públicas: aspectos conceituais, metodológicos e abordagens teóricas. Revista do Direito, Santa Cruz do Sul, v. 3, n. 56, jan. 2019.

SILVA, Daniela Madruga Rego Barros Victor; PEDROSO, Vanessa Alexsandra de Melo. A concretização do direito à moradia como direito fundamental social: desafios do século XXI. p. 89. Disponível em: file://C:/Users/CCE/Dropbox/My\%20PC\%20 (DESKTOP-69HABGU)/Downloads/a\%20concretização\%20do\%20direio\%20a\%20moradia.pdf. Acesso em: 2 nov. 2020.

SOUZA, Marcos Felipe Alonso de. O meio ambiente urbano em face do Estatuto da Cidade: importância e implicações da lei 10.257/01para as sociedades urbanas. Disponível em: http://www.cognitiojuris.com/artigos/03/06.html. Acesso em: 28 nov. 2020.

STEFANIAK, João Luiz; STEFANIAK, Jeaneth Nunes. A cidade ilegal e o Estatuto da Cidade: análise da efetividade dos instrumentos de regularização fundiária. Disponível em: file://C:/Users/CCE/Dropbox/My\%20PC\%20(DESKTOP-69HABGU)/Downloads/ 2543-Texto\%20do\%20artigo-14375-1-10-20120613\%20(1).pdf. Acesso em: 29 nov. 2020.

SUBIRATS, Joan et al. Análisis y gestión de políticas públicas. Barcelona: Planeta, 2012. 